\title{
Moisture Effects on Copper Thin Film Adhesion
}

\author{
Patrick J. Waters, Alex A. Volinsky, \\ Department of Mechanical Engineering, University of South Florida \\ volinsky@eng.usf.edu
}

\begin{abstract}
The effects of moisture on copper thin film adhesion have been investigated using a modified version of the superlayer indentation test. Copper films up to $100 \mathrm{~nm}$ thick were sputter deposited on thermally oxidized silicon wafers. A $1 \mu \mathrm{m}$ tungsten superlayer with $1 \mathrm{GPa}$ compressive residual stress was sputter deposited on top of $\mathrm{Cu}$ films, providing extra energy for interfacial debonding upon indentation. The samples were first indented to a depth just greater than the thickness of the $\mathrm{W} / \mathrm{Cu}$ bi-layer and then unloaded. Water was introduced to the indent, and a second higher load indent was made in the exact same location as the first one to drive crack propagation in the wet environment. For the indents made to the same maximum load, there was a dramatic increase in blister size in the wet environment compared to the blister size in the dry environment. Copper film adhesion in the presence of water was up to 20 times lower than in the dry environment $\left(0.1 \mathrm{~J} / \mathrm{m}^{2}\right.$ vs. $\left.2 \mathrm{~J} / \mathrm{m}^{2}\right)$. Chemical reactions at the crack tip along with the surface energy minimization by water are thought to be the causes for the adhesion reduction.
\end{abstract}

\section{Introduction}

Thin films are found everywhere, from the paint on a car to the interconnects in a computer microprocessor. There is an endless variety of applications based on the various functional properties of thin films. Thin films are used in information storage, optics, microelectronics, in biomedical and other fields. These applications are possible because of the thin films' magnetic, reflective, electrical, mechanical and other properties [1-6]. With the growing number of uses for thin films, there will be an increase in the variety of environments in which these thin films will be operating. That is why environmental effects on film adhesion need to be studied. For the current research, copper films were considered, being the replacement for aluminum interconnects in microelectronic devices. Not only does copper have better electrical and thermal conductivity than aluminum, copper interconnects provide higher current densities and better electromigration performance. However, one major disadvantage of using copper thin films is that they have lower adhesion to substrates compared to aluminum films.

This paper considers the effects of water on copper film adhesion which have been investigated using a modified version of the superlayer indentation test. Copper films up to $100 \mathrm{~nm}$ thick were sputter deposited on thermally oxidized silicon wafers. A $1 \mu \mathrm{m}$ thick layer of tungsten with high compressive residual stress was sputter deposited on top of the copper films. The tungsten superlayer is used to restrict plastic pile up of the copper layer around the indenter tip and to help drive interfacial debonding upon indentation. With the superlayer having high compressive residual stress, it provides additional energy, helping to propagate a crack along the film/substrate interface. The use of the superlayer residual stress allows for lower externally applied loads needed to induce thin film delamination.

If the proper thin film deposition conditions are not met, high residual stresses may be present in the thin film, ultimately leading to its failure. Residual stresses can be partially relieved through plastic deformation, cracking, or delamination. Tensile residual stresses usually lead to film cracking and interfacial delamination, while compressive residual stresses typically lead to film buckling and delamination from the substrate. For most cases high residual stress is not desired, but here it is utilized for measuring thin film adhesion.

\section{Experimental Procedure}

Copper films of two different thicknesses were tested (67 and $97 \mathrm{~nm}$ thick). The analysis used for calculating film adhesion is based on the Marshall and Evans approach of treating the delaminated film section as a rigidly clamped disc [7]. Two problems likely to be encountered in a single layer indentation test are pile-up of the thin film around the indenter tip and penetration to depths greater than the film thickness. If the indent is made too deep, deformation and cracking of the substrate may occur, reducing the test validity.

Both problems can be avoided by using the superlayer indentation technique $[1,8]$. The superlayer can be deposited by means of sputtering, where the temperature is not high enough to alter the microstructure and the interfacial properties of the original film. The superlayer can be tailored to optimize conditions for film thickness and residual stress, which allows for a greater delamination driving force for the same penetration depth to the film thickness ratio. One condition that must be met for the superlayer indentation method to work is that the superlayer must adhere to the film more strongly than the film adheres to the substrate. If this 
condition is not met, the adhesion measurement obtained will be for the superlayer to the film and not the adhesion of the film of interest to the substrate.

Kriese and Gerberich further developed the test to take into account the sample geometry by applying the laminate theory for calculating the strain energy release rates for multilayer samples [8]. For the case where the superlayer is much thicker than the underlayer, the single layer analysis can still be applied as defined by Marshall and Evans [7]. In addition to knowing the sample geometry and the elastic properties of each layer, two physical measurements, namely the delamination blister radius, $\mathrm{x}$ (Figure 1) and plastic indentation depth, $\delta$ (Figure 2) are required for calculating thin film adhesion.

The copper films were first tested in a dry environment, where three different trials of indents were made at different locations on the sample. Each trial consisted of 10 indents in order to get good statistical variation and calculate an average adhesion value. Changes in residual stress of up to $25 \%$ can be observed across a 6" wafer and will affect adhesion measurements when using the superlayer indentation technique [9].

Indents were made to a range of maximum loads in order to obtain the steady state strain energy release rate value, which can be equated to the film adhesion. The load range for indentation in the dry environment was kept between 100 and $250 \mathrm{mN}$. For indents made below a $100 \mathrm{mN}$ load, delamination blisters were small, almost indistinguishable in the optical microscope. For indents made to greater than a $250 \mathrm{mN}$ load, radial cracks in the buckled thin film and the substrate were present making adhesion measurements inaccurate. After several indents were performed, film adhesion was plotted against the $\mathrm{x} / \mathrm{a}$ ratio (Figure 4 and Figure 5). Here, $x$ is the delamination blister radius and $a$ is the tip contact radius defined in Figure 1.

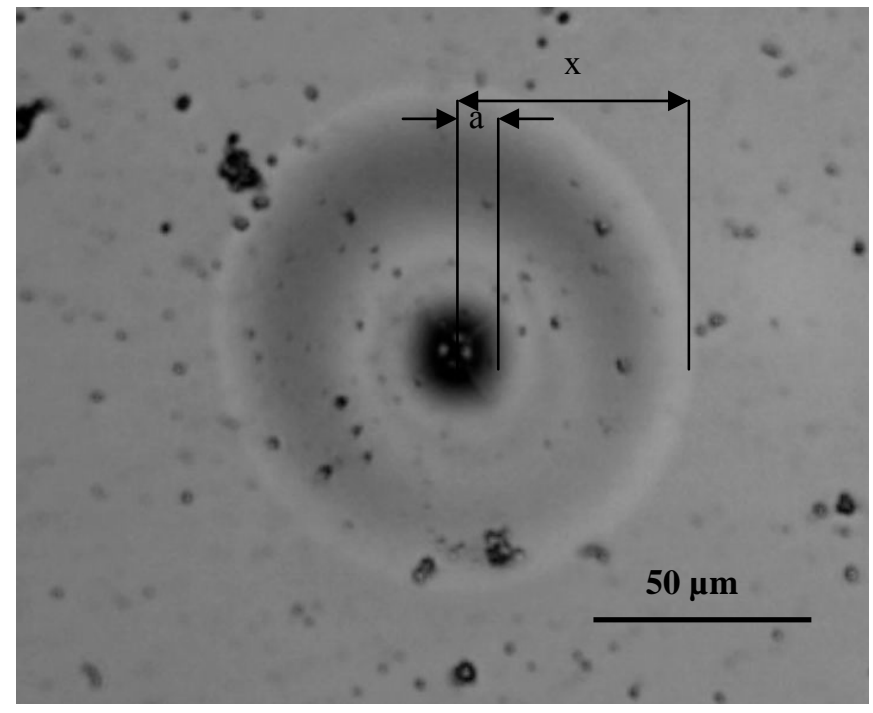

Figure 1. Delamination blister radius and contact radius.

Adhesion measurements in a wet environment were conducted using a modified version of the superlayer indentation test. An introductory indent was first performed to a depth just greater than the thickness of the $\mathrm{W} / \mathrm{Cu}$ bi-layer and then the tip was unloaded. Water was introduced to the indentation, followed by a second indent in the exact same location as the first one in order to further drive the crack propagation in the moist environment. Conventional superlayer indentation test analysis for calculating the strain energy release rate was used for the double indent test, where the plastic indentation depth and the delamination blister radius are the two measurements required.

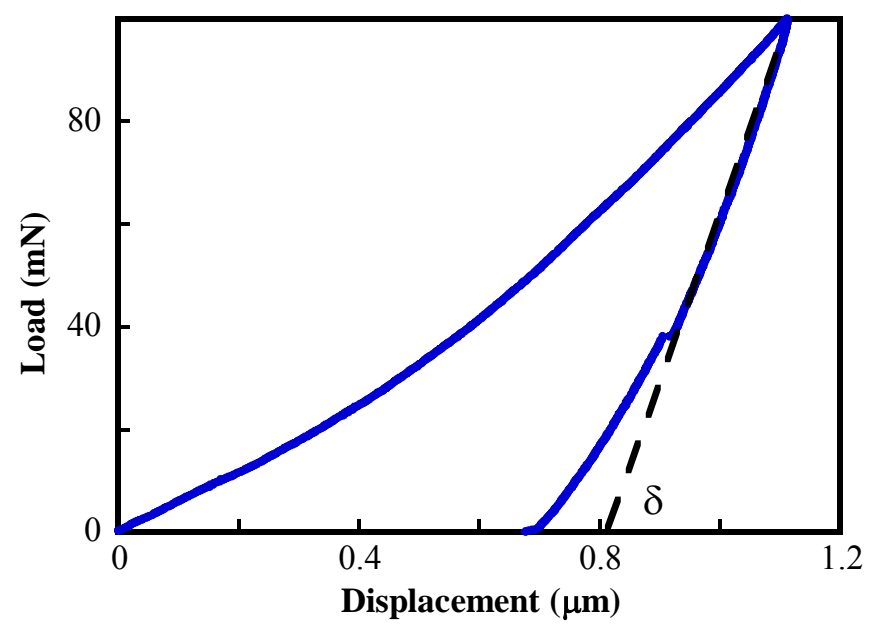

Figure 2. Load-displacement curve: Plastic indentation depth determination.

Before conducting the double indentation test in water, it was first carried out in a dry environment and compared with the same load single indent test. Results presented in Figure 3 and Table 1 show that for the same $\mathrm{x} / \mathrm{a}$ ratio, the strain energy release rate was comparable for the single and double indent tests in a dry environment, proving the test validity.

It should be noticed that for the second indent in the double indent test, the real time load-displacement plot starts from the depth where the introductory indent ended. Since the nanoindenter records the first contact point at zero displacement, the second load-displacement curve was manually shifted to account for this effect (Figure 3).

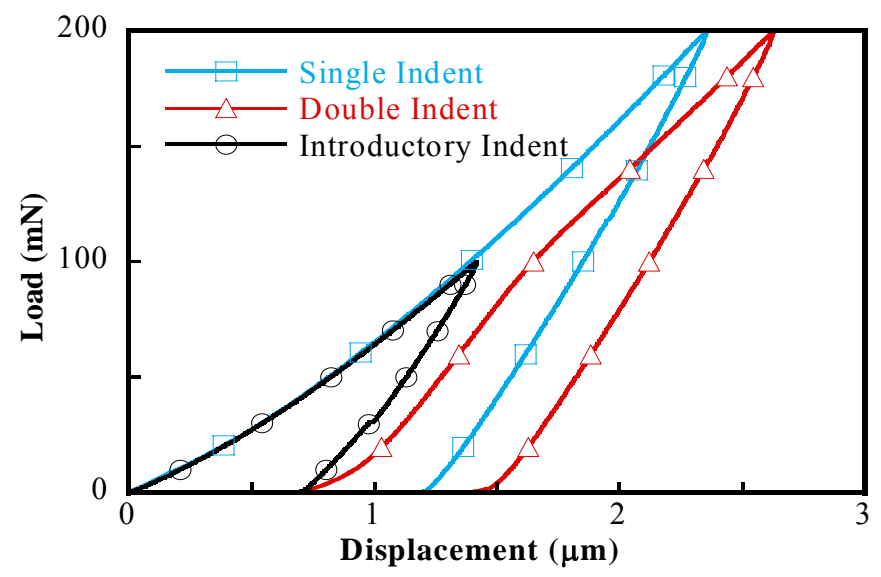

Figure 3. Single and double indents conducted in a dry environment. 
Table 1. Double and single indentation test results.

\begin{tabular}{|c|c|c|}
\hline Sample & Blister Diameter $(\mu \mathrm{m})$ & $\mathrm{G}\left(\mathrm{J} / \mathrm{m}^{2}\right)$ \\
\hline Cu 67 nm (Dry) & $20 \pm 5.0$ & $2.74 \pm 0.86$ \\
\hline Cu 67 nm (Wet) & $\mathbf{1 5 0} \pm \mathbf{1 5}$ & $\mathbf{0 . 1 5} \pm \mathbf{0 . 0 5}$ \\
\hline Cu 97 nm (Dry) & $20 \pm 5.0$ & $1.98 \pm 0.82$ \\
\hline Cu 97 nm (Wet) & $\mathbf{1 5 0} \pm \mathbf{2 0}$ & $\mathbf{0 . 1 0} \pm \mathbf{0 . 0 1}$ \\
\hline
\end{tabular}

\section{Results and Discussion}

For the indents performed in the dry environment the steady state strain energy release rate was observed for $\mathrm{x} / \mathrm{a}$ ratios greater than 8 (Figure 4 and Figure 5). For smaller indents, where $\mathrm{x} / \mathrm{a}<5$, there is predominantly indentationinduced stress that drives interfacial delamination. For $\mathrm{x} / \mathrm{a}$ ratios greater than 5 , the residual stress in the superlayer is the largest contributing factor for interfacial crack growth [10]. For x/a ratios between 9 and 12 the steady state strain energy release rate is equal to the thin film adhesion.

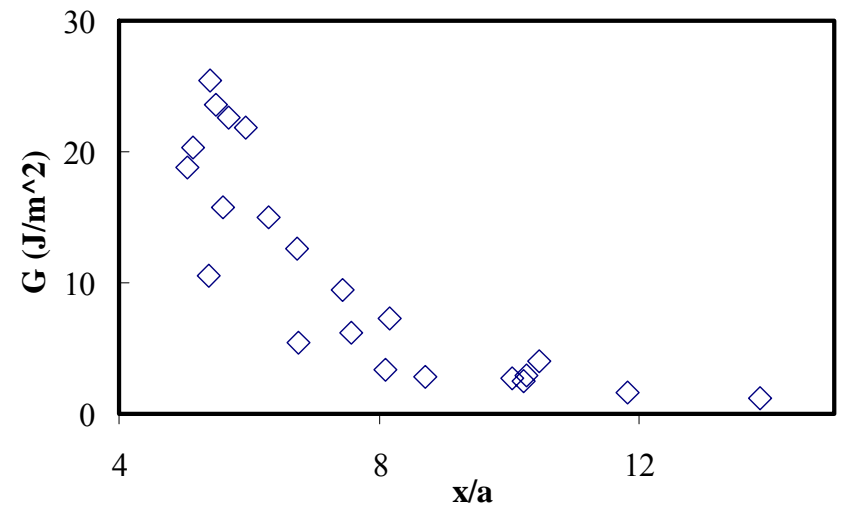

Figure 4. Strain energy release rate for the $67 \mathrm{~nm}$ copper film.

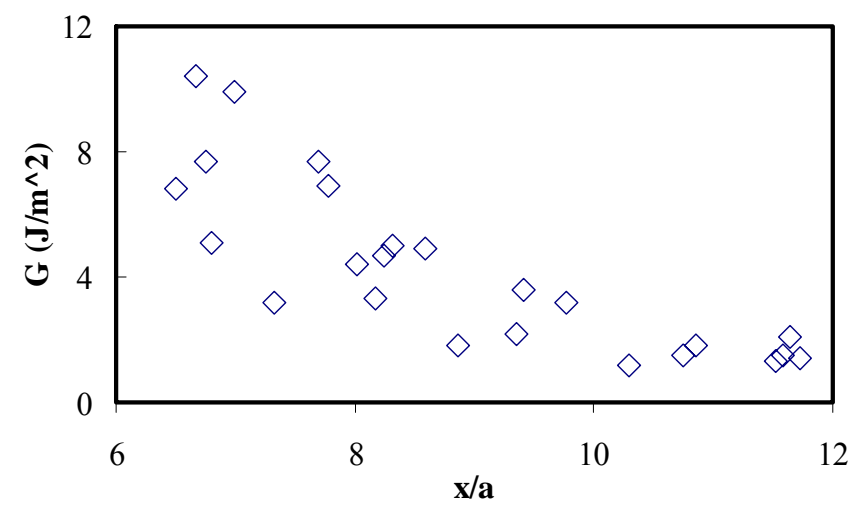

Figure 5. Strain energy release rate for the $97 \mathrm{~nm}$ copper film.

In order to notice moisture effects on thin film adhesion, water must be able to reach the film/substrate interface. Before the double indentation test was performed, water was first placed on the surface of the film and then the film was indented. No changes in film adhesion were noticed with this procedure, similar to when the introductory indent in the double indentation test did not reach a depth equal to the film stack thickness.

For indents performed in a wet environment with a deep enough introductory indent and with a second indent to the same maximum load as a single indent in a dry environment, larger delamination blister radii were immediately noticed. For both copper samples, the blister diameter for a $150 \mathrm{mN}$ indent in the dry environment was approximately $20 \mu \mathrm{m}$ and increased up to $150 \mu \mathrm{m}$ when the double indent was made in the wet environment to the same maximum load (Figure 6).

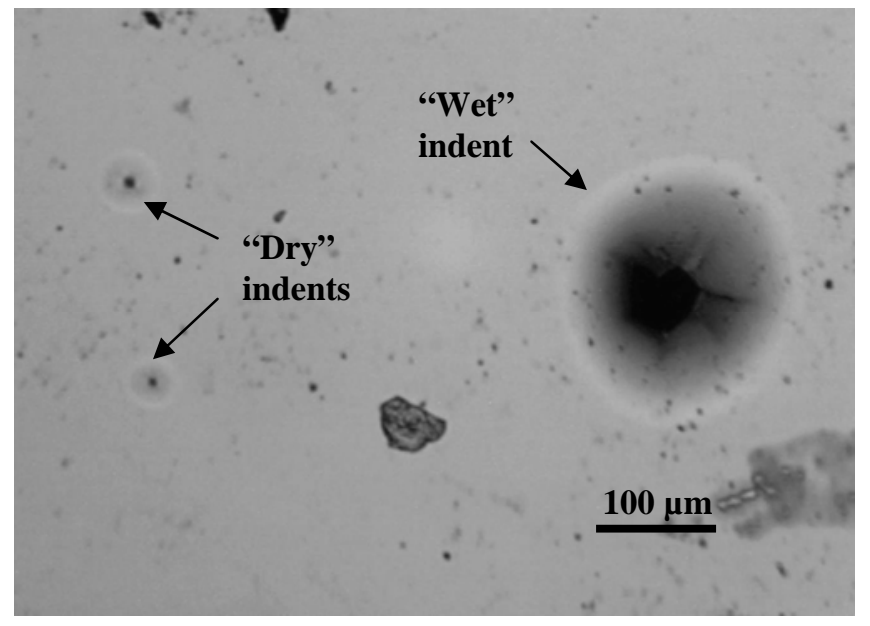

Figure 6. Delamination blisters in wet and dry environments.

Adhesion measurements in the wet environment for both copper samples showed a reduction in adhesion by a factor of 10 to 20 compared to those performed in the dry environment. For the $67 \mathrm{~nm}$ thick copper sample the average adhesion in water was $0.15 \mathrm{~J} / \mathrm{m}^{2}$, compared to $2.74 \mathrm{~J} / \mathrm{m}^{2}$ in air, and for the $97 \mathrm{~nm}$ thick sample it was $0.10 \mathrm{~J} / \mathrm{m}^{2}$ vs. $1.98 \mathrm{~J} / \mathrm{m}^{2}$ in air (Table 2).

Table 2. Comparison of wet and dry adhesion results.

\begin{tabular}{|c|c|c|c|}
\hline Indent Procedure & $\begin{array}{c}\text { Maximum } \\
\text { Load }(\mathrm{mN})\end{array}$ & $\mathrm{x} / \mathrm{a}$ & $\mathrm{G}\left(\mathrm{J} / \mathrm{m}^{2}\right)$ \\
\hline $\begin{array}{c}\text { Double Indent } \\
\text { (Dry) }\end{array}$ & 200 & $7-8$ & $7.8 \pm 0.3$ \\
\hline $\begin{array}{c}\text { Single Indent } \\
\text { (Dry) }\end{array}$ & $225-250$ & $7-8$ & $8.1 \pm 0.5$ \\
\hline
\end{tabular}

Along with the significantly larger delamination blister sizes there was also a load excursion seen in the loaddisplacement curve (Figure 7). Similar load excursions were also observed in the dry environment, but at much higher applied loads. 


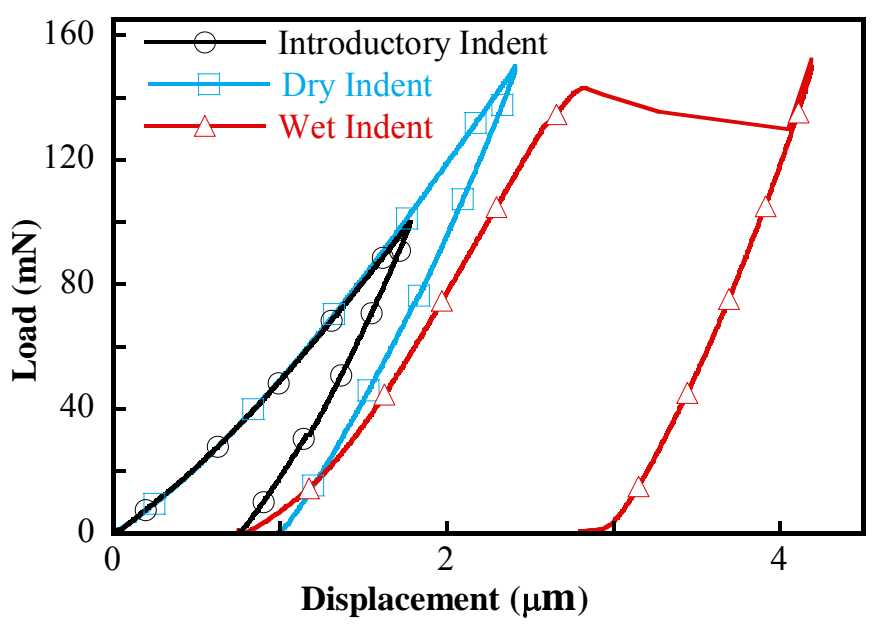

Figure 7. Load-displacement curves for indents performed in wet and dry environments: Load excursion in a wet environment.

Initially, the reason for a $\mathrm{Cu}$ adhesion reduction was thought to be due to $\mathrm{Cu}$ oxidation at the crack tip during the delamination process. Oxidation of the $\mathrm{Cu}$ films is supported by previous findings for the $\mathrm{Ta} / \mathrm{SiO}_{2}$ interface $[11,12]$. The tantalum films were tested using the four point bend test, where increase in the crack propagation velocity was seen with an increase in relative humidity. Equation 1 shows a possible reaction of copper and water at the film/substrate interface.

$$
2 \mathrm{Cu}+\mathrm{H}_{2} \mathrm{O} \rightarrow \mathrm{Cu}_{2} \mathrm{O}+2 \mathrm{H}^{+}
$$

Oxidation of copper at the crack tip can reduce film adhesion, as the copper oxide is approximately two times harder than pure copper. Copper oxide at the interface may restrict the amount of plasticity at the crack tip. If that is the case, less energy would be dissipated by plastic deformation. Usually, the thicker the metal film, the larger the plastic zone size ahead of the crack tip, leading to higher adhesion values, although, for the copper films thinner than a $100 \mathrm{~nm}$, almost no plasticity at the crack tip was observed [13]. Also, hydrogen can cause metal film embrittlement $[14,15]$

Additionally, we performed adhesion measurements of diamond like carbon (DLC) films on $\mathrm{Si}$ with a $100 \mathrm{~nm} \mathrm{\textrm {SiO } _ { 2 }}$ layer. The DLC films showed a 50-fold reduction in film adhesion. Since DLC films are chemically inert [16, 17], oxidation at the DLC film crack tip was ruled out as the adhesion weakening mechanism. $\mathrm{A} \mathrm{SiO}_{2}$ layer was a common factor between the copper and DLC film stacks. A chemical reaction could be taking place between the water and the $\mathrm{SiO}_{2}$ similar to environmentally assisted fracture in bulk glasses [18].

If the reduction in adhesion is not due to a chemical reaction at the crack tip, it could be explained by lowering of surface energy at the interface in the controlled (moisture) environment. From a thermodynamic perspective, the true work of adhesion at the interface is the amount of energy required to create two free surfaces from the bonded materials. For an ideal case of brittle fracture, the true work of adhesion can be defined as the film/substrate adhesion and there is no energy dissipated due to plastic deformation. All energy is conserved as new surfaces are formed:

$$
W_{A}=\gamma_{f}+\gamma_{s}-\gamma_{f s}
$$

where $\gamma_{f}$ is the surface energy of film, $\gamma_{s}$ is the surface energy of the substrate and $\gamma_{f s}$ is the interfacial energy. This follows the idealized case of Griffith fracture where the fracture resistance, $\Gamma_{i}$, is assumed to be equal to the thermodynamic (true) work of adhesion, $W_{A}$. When the strain energy release rate, $G$, is greater than the fracture resistance the crack will propagate.

$$
G \geq \Gamma_{i}
$$

If the surface energy decreases with the presence of water, the true work of adhesion will decrease and less energy would be needed to create two new surfaces. That would explain why larger delamination blisters were induced in the presence of water compared to the dry environment for the same maximum loads used.

\section{Conclusions}

It has been observed that film adhesion is dramatically reduced by the introduction of water at the film/substrate interface. The water must reach the interface between the film and the substrate in order for this effect to be seen. When the introductory indent did reach the interface, copper film adhesion was reduced by a factor between 10 and 20. This reduction is thought to be due to either a chemical reaction, causing hydrogen embrittlement, or due to lowering the surface energy when water reaches the crack tip. More research needs to be conducted to determine what role $\mathrm{SiO}_{2}$ underlayer plays in the adhesion reduction. It is still undetermined whether the chemical effects and hydrogen embrittlement at the crack tip are prevailing over the water lowering the surface energy.

Controlling residual stresses in thin films is a critical factor in the microelectronics industry. It has been shown that high residual stresses are to be avoided, especially when processes such as chemical mechanical planarization are involved, where thin films are exposed to external forces and chemically active fluids. Future work will be conducted on the possibility of controlling delaminations in highly compressed thin films. When the residual stress is at least four times the critical buckling stress, telephone cord delaminations may appear [9, 19]. In films where residual stresses are high enough and film adhesion is low, the introduction of water has been observed to propagate thin film buckling delamination (Figure 8) [20].

Delamination propagation continues until the water is removed or the delamination reaches the edge of the sample. These delamination channels can be used for fluid transport in biomedical applications [21]. Additional tests will be conducted to further explore water effects on thin film adhesion, and how these effects could be employed for 
producing delamination channels for microfluidic applications.

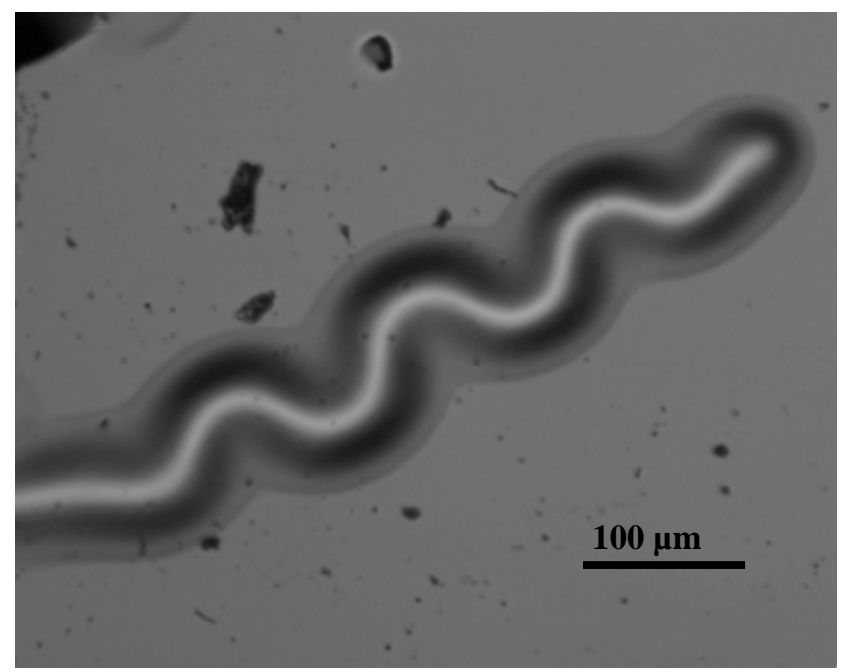

Figure 8. Propagation of a telephone cord delamination with the introduction of water.

\section{Acknowledgements}

The authors would like to acknowledge the financial support for this research from NACE International under contract N000140210024. PW would like to acknowledge the support from Seagate Technology under the Summer Internship Program. DLC samples were prepared by Seagate Research. Consequent W deposition was performed at Washington State University in D. Bahr's group. AV would like to acknowledge the support from the Marie Curie Host Fellowship for the Transfer of Knowledge under the project "Nano-engineering for Expertise and Development - NEED" within the $6^{\text {th }}$ EU Framework Program.

\section{References}

1. A.A. Volinsky, N.R. Moody, W.W. Gerberich, Acta Mater. 50, pp. 441-466 (2002)

2. H. Jeong, S. Hata, A. Shimokohbe, J. MEMS 12, pp. 42$52(2003)$

3. X. Sun, Z. Jiang, S. Xin, Z. Yao, Thin Solid Films 471, pp. 194-199 (2005)

4. R. Bryce, H. Nguyen, P. Nakeeran, T. Clement, C. Haugen, R. Tykwinski, R. DeCorby, J. McMullin, Thin Solid Films 458, pp. 233-236 (2004)

5. T.R. Hsu, 'MEMS and Microsystems Design and Manufacture', McGraw-Hill, New York (2002)

6. M. Ohring, "The Materials Science of Thin Films", Academic Press, London (1992)

7. D.B. Marshall, A.G. Evans, J. Appl. Phys. 56, pp. 26322638 (1984)

8. M.D. Kriese, W.W. Gerberich, N.R. Moody, J. Mat. Res. 14, pp. 3007-3018 (1999)
9. A.A. Volinsky, Mat. Res. Soc. Symp. Proc. Vol. 749, W10.7 (2003)

10. A.A. Volinsky, N. Tymiak, M.D. Kriese, W.W. Gerberich, Mat. Res. Soc. Symp. Proc. 539, pp. 277-290 (1999)

11. M.W. Lane, J.M. Snodgrass, R.H. Dauskardt, Microelectronics Reliability 41, pp. 1615-1624 (2001)

12. M.W. Lane, R.H. Dauskardt, J. Mat. Res., 15, pp. 203$211(2000)$

13. N.I Tymiak, A.A. Volinsky, M.D. Kriese, S. Downs, W.W. Gerberich, Met. Mat. Trans. A 31, pp. 863-871 (2000)

14. V.M. Kornev, J. Appl. Mech. Tech. Phys. 39, pp. 173178 (1998)

15. N.I. Tymiak, M. Li, A.A. Volinsky, Y. Katz, W.W. Gerberich, Mat. Res. Soc. Symp. Proc., 563, pp. 269-274 (1999)

16. S.J. Cho, K.R. Lee, K.Y. Eun, J.H. Jeong, D. Kwon, Diamond \& Related Mater. 8, pp. 1067-1072 (1999)

17. M. Suzuki, T. Ohana, A. Tanaka, Diamond \& Related Mater. 13, pp. $2216-2220$ (2004)

18. S. Wiederhorn, J. Ceram. Soc. 50, pp. 407-413 (1967)

19. M. Moon, K. Lee, K. Oh, J.W. Hutchinson, Acta Mat. 52, pp. 3151-3159 (2004)

20. A.A. Volinsky, P.J. Waters, J.D. Kiely, E. Johns, Mat. Res. Soc. Symp. Proc. 854E, (2004)

21. A.A Volinsky, P.J Waters, G. Wright, Mat. Res. Soc. Symp. Proc. Vol. 855E, W3.16, 2004 